\title{
Docencia en tiempos de Covid19
}

\author{
Teaching in times of Covid 19
}

\author{
Max Turull Rubinat \\ IDP/ICE \\ Facultad de Derecho, Universidad de Barcelona \\ E-mail: $\underline{\text { mturull@ub.edu }}$
}

La pandemia desatada por la Covid19 ha provocado en muchos países del mundo el cierre de las universidades y la suspensión de la actividad docente presencial. En España esto se produjo en la primavera del 2020, con la aprobación por el Gobierno del Estado del Real Decreto 463/2020, de 14 de marzo, por el que se declara el estado de alarma para la gestión de la situación de crisis sanitaria ocasionada por el COVID-19.

Prácticamente de un día para otro las universidades presenciales, que son la mayoría, se vieron empujadas a una situación inédita para ellas. Se suspendía toda la docencia presencial y lo que quedaba de curso, que aún era mucho, discurría por cauces virtuales. Por lo general, la primera reacción de las universidades fue dar a conocer recursos de tecnología docente entre su profesorado para ser utilizados en modo virtual. En pocas semanas hubo un auténtico diluvio de posibilidades de lo más dispar. Lo cierto es que el profesorado, ante tanta "oferta", hizo lo que pudo y como pudo, a menudo de manera individual. Salvo excepciones, en aquel momento no se dictaron directrices institucionales claras sobre como reorientar la docencia. Sí, por supuesto, las universidades y los centros reaccionaron y publicaron declaraciones sobre cómo debía actuar su personal, en general en aquello relativo a la higiene y la salud. Pero consignas estrictamente docentes, disponiendo como había que actuar, hubo pocas. La diversidad fáctica de situaciones fue enorme: en un mismo departamento, impartiendo una misma asignatura, podíamos observar prácticas totalmente distintas. Puede objetarse que también es variada la metodología docente en tiempos de normalidad. Pero ante una 
situación de auténtica crisis, que cada docente actuara a su antojo podía conducir a situaciones poco deseables. De hecho los medios de comunicación empezaron a dar a conocer casos de descontento del estudiantado ante la pasividad o falta de reacción de ciertos docentes. Muchos empezamos a recurrir, de manera intensiva, a los recursos que ya conocíamos: ofrecer esquemas, mapas conceptuales, presentaciones, lecciones, resúmenes, etc. a los estudiantes a través del campus virtual; otros descubrimos "nuevas" potencialidades con recursos bien ordinarios (como introducir vídeos o audios en las presentaciones, generar y distribuir vídeos domésticos más o menos breves con las lecciones); otros más también empezamos a probar los nuevos recursos que se nos proporcionaban, especialmente las videoconferencias; también se empezó a sacar más provecho de las enormes utilidades de los campus virtuales de la plataforma Moodle, o cualquier otra. Pero también conviene reconocer que emergieron, aunque fuese minoritario, casos poco honrosos o poco comprometidos. Al lado del docente comprometido, también apareció el docente que se limitó a mandar algunos correos a sus estudiantes con la bibliografía que ya había sido recomendada y el docente que apenas jamás había utilizado el campus virtual. Sea como fuere, poco a poco cada uno, de manera estrictamente individual -ciertas facultades o disciplinas poseen una profunda cultura académica al respecto- o con cierta coordinación departamental, acabó estabilizando un cierto ecosistema docente adaptado a la nueva situación que la pandemia había provocado. Creo que no me equivocaría mucho si lanzase la generalización de que en aquella ocasión la universidad española hizo poca política docente.

El curso 2020-2021 ha nacido bajo condiciones diferentes. La pandemia todavía no se ha vencido pero en la mayoría de países del hemisferio norte, y España entre ellos, las universidades han reabierto sus puertas, no sin grandes dosis de incerteza. Ha habido tiempo para que las autoridades académicas, a pesar de la incertidumbre crónica de la situación, planificaran la vuelta a las aulas. Ahora sí que ha habido que desarrollar, con más o con menos acierto y más o menos profundidad, políticas docentes a diferentes niveles. No podía ser de otra manera.

En general se ha tenido en cuenta la especificidad de la docencia de primer curso de grado, cuando el estudiante ingresa en la universidad y conviene un proceso de socialización y de aprehensión del nuevo medio, y la docencia de cursos superiores de grado o de máster. Aparte de la naturaleza o singularidad del estudiante (primer curso, grado, máster, etc.), en el nuevo entorno la modalidad de la docencia se articula sobre todo en base al binomio presencialidad/virtualidad, y, sobre el segundo elemento, sobre el eje sincronía/asincronía. 
Mientras que para primer curso en general se está optando por una porción significativa de presencialidad -dispar según número de alumnos matriculados y capacidad de las aulas para garantizar una distancia de seguridad-, en cursos superiores y máster las opciones pueden ser bien dispares según las circunstancias académicas. En ciertos casos, cuando los grupos siguen siendo numerosos, se tiende a apostar más por la docencia on line; pero en otros casos, cuando la matriculación es más discreta, se puede optar por mayor presencialidad. Pero esta modalidad on line puede revestir por lo menos dos opciones distintas: la sincrónica y la asincrónica. Se da la primera, por ejemplo, cuando una parte del alumnado está presente en el aula y la otra parte sigue la misma sesión por streaming, cada cual desde su domicilio o desde una instalación de la universidad. Ya aquí aparecen diferentes posibilidades: docencia alternativa presencial y on line por streaming por subgrupos en días o semanas alternas (el programa del profesor avanza sin repeticiones y los alumnos presentes van alternando), o el profesor repite la sesión presencial a cuantos subgrupos han sido creados. En la sesión asincrónica no hay simultaneidad de tiempo -por supuesto que tampoco de espacio- y el docente o la institución ponen al servicio del estudiante una grabación de vídeo que puede consultar en cualquier momento y tantas veces como lo desee. En este proceso hay matices y posibilidades técnicas y numerosas dudas sobre propiedad intelectual y derecho a la imagen que no escapan al jurista. El estudiante puede visionar un vídeo, pero ¿puede descargarlo?, ¿puede editarlo?, ¿puede difundirlo?, ¿bajo qué condiciones?, etc...

Pero hasta aquí podríamos convenir que se trataba hasta cierto punto de un tema organizativo. La organización de la docencia no es un aspecto menor, pues puede influir poderosamente en los resultados académicos alcanzados e incluso en la calidad de la docencia. Más sutil y quizá más determinante sea definir cómo utilizamos la porción de la docencia que transita de manera virtual, bien sea sincrónica o asincrónica. O sea, ¿qué hacemos en las sesiones on line? Una primera reacción, como un tic de la institución y del profesorado habituado a lo presencial, es intentar reproducir el esquema presencial al nuevo medio virtual. O sea, reproducir, por ejemplo, la clase magistral, que puede funcionar muy bien en el medio presencial, al formato virtual, lo que ofrece resultados más discutibles. No son excepción, y menos en Derecho, los docentes que han dado clases virtuales de dos horas por videoconferencia ante un auditorio por lo general anónimo, invisible y mudo. Si mantener la atención en vivo y en directo ya es difícil, qué no va a ser hacerlo por videoconferencia a menudo sin ver el rostro de los estudiantes y por tanto sin el más mínimo feedback comunicativo. 
Nos preguntamos si no sería mejor, y más efectivo para el aprendizaje, dedicar las sesiones virtuales a plantear un tema o a ofrecer las pautas y líneas de estudio de una lección; o bien, en otro sentido, complementario, a conducir una síntesis del tema que los estudiantes han trabajado previamente; o, todavía, a resolver ejercicios o casos prácticos, a resolver dudas y establecer conclusiones para cerrar un bloque de estudio. Pero quizá también convenga que el estudiante escuche activamente una clase magistral, ¿por qué no? En todo caso, lo que vayamos a hacer con la sesión virtual debería ser el resultado de una cierta reflexión particular e institucional- y no el resultado de la inercia y de la repetición acrítica de lo que siempre hemos hecho, en un universo presencial.

No querría cerrar esta breve presentación sin plantear dos breves reflexiones que nos atañen directamente: una relacionada con la práctica de nuestros estudiantes y otra con nuestra propia práctica docente.

En el primer caso, podría decirse que tropezamos de lleno y casi sin saberlo ante el famoso aprendizaje autónomo. Los buenos pedagogos nos han contado, sin jergas innecesarias, que el aprendizaje autónomo no consiste en dejar que el estudiante se espabile completamente por su cuenta, como si debiera sobrevivir en una selva, sino en conducirle, aportando recursos, pautas y saberes, a construir verdadero conocimiento. A menudo se ha vinculado el aprendizaje autónomo con el aprendizaje profundo, algo parecido al verdadero y único aprendizaje. El escenario provocado por la pandemia nos sitúa ante el aprendizaje autónomo, con lo positivo y lo negativo que ello comporta. Es muy posible -y sería conveniente realizar alguna investigación empírica al respecto- que en esta docencia híbrida o semipresencial o mixta, algunos estudiantes no mermen su aprendizaje sino incluso al contrario, que su aprendizaje sea mayor y mejor. Y es que la coyuntura les habrá obligado a ser más protagonistas de su experiencia de aprendizaje y a utilizar recursos de aprendizaje más potentes, como, sencillamente, leer libros en lugar de apuntes de clase. Pero por esta misma razón también habrá el estudiante del polo opuesto, que no tendrá la habilidad suficiente para construir aprendizaje autónomo y que estará desorientado si no se le ofrece un plato completamente cocinado. La función del profesor, en este segundo caso, todavía es más importante porque debe intentar revertir una situación claramente adversa.

Desde nuestra posición docente, y ahondando en la reflexión que antes estimaba imprescindible, creo que es importante que no nos dejemos deslumbrar ante la variedad y la riqueza de la tecnología docente. Y decimos deslumbrar en el sentido literal de la palabra, 
cuando una luz intensa que te enfoca directamente a los ojos te impide ver qué hay en un lugar. En un reciente seminario de RED-U, se insistía que no es cuestión de tecnología sino de modelo. Efectivamente, las presentaciones con audio o con video, las sesiones por videoconferencia, las tutorías virtuales, las reuniones on line (todas con programas cada vez más llamativos, potentes y sofisticados), los ejercicios de respuesta múltiple del campus y cualquier otro recurso, tecnológico o no, son eso: recursos. Son instrumentos para alcanzar objetivos. Antes el recurso o el instrumento principal quizá eran la clase presencial, la lección magistral presencial o la realización de ejercicios prácticos ante el profesor. Ahora los recursos o instrumentos han cambiado, pero siguen siendo recursos y en ningún caso se han convertido en objetivos en sí mismos. Por tanto conviene hacer un cierto esfuerzo por mantener la alineación constructiva. Debemos mantener perfectamente alineados los objetivos de aprendizaje -que pueden no haber variado sustancialmente con la pandemia-, la metodología y los recursos, y la evaluación. Una, o quizás dos, de las piezas han debido ser sustituidas por otras, pero deben seguir alineadas con los objetivos de aprendizaje que nos hemos planteado. 